\title{
Crosstalk and differential response to abiotic and biotic stressors reflected at the transcriptional level of effector genes from secondary metabolism ${ }^{\star}$
}

\author{
Sabine Glombitza ${ }^{1, \dagger}$, Pierre-Henri Dubuis ${ }^{2, \dagger}$, Oliver Thulke ${ }^{1}$, Gerhard Welzl ${ }^{1}$, Lucien \\ Bovet $^{2,3}$, Michael Götz ${ }^{1}$, Matthias Affenzeller ${ }^{1}$, Birgit Geist ${ }^{1}$, Alain $\mathrm{Hehn}^{4}$, Carole \\ Asnaghi $^{4}$, Dieter Ernst ${ }^{1}$, Harald K. Seidlitz ${ }^{1}$, Heidrun Gundlach ${ }^{1}$, Klaus F. Mayer ${ }^{1}$, \\ Enrico Martinoia $^{5}$, Daniele Werck-Reichhart ${ }^{4}$, Felix Mauch ${ }^{2}$ and Anton R. Schäffner ${ }^{1, *}$ \\ ${ }^{1}$ Institute of Biochemical Plant Pathology, Institute of Developmental Genetics, Institute of Bioinformatics, \\ MIPS, and Institute of Soil Ecology, Department of Environmental Engineering, GSF - National Research \\ Center for Environment and Health, D-85764 Neuherberg, Germany (*author for correspondence; e-mail \\ schaeffner@gsf.de); ${ }^{2}$ Department of Biology, University of Fribourg, CH-1700 Fribourg, Switzerland; \\ ${ }^{3}$ Institute of Plant Sciences, University of Bern, CH-3013 Bern, Switzerland; ${ }^{4}$ Department of Plant Stress \\ Response, Institute of Plant Molecular Biology, CNRS-UPR2357, Université Louis Pasteur, F-67083 \\ Strasbourg Cedex, France; ${ }^{5}$ Plant Biology - Molecular Plant Physiology, University of Zurich, CH-8008 \\ Zurich, Switzerland; ${ }^{\dagger}$ contributed equally to this work
}

Received 7 January 2004; accepted in revised form 10 May 2004

Key words: gene families, glutathione-dependent enzymes, glycosyltransferases, herbicides, pathogen, stress hormones

\begin{abstract}
Plant secondary metabolism significantly contributes to defensive measures against adverse abiotic and biotic cues. To investigate stress-induced, transcriptional alterations of underlying effector gene families, which encode enzymes acting consecutively in secondary metabolism and defense reactions, a DNA array (MetArray) harboring gene-specific probes was established. It comprised complete sets of genes encoding 109 secondary product glycosyltransferases and 63 glutathione-utilizing enzymes along with 62 cytochrome P450 monooxygenases and $26 \mathrm{ABC}$ transporters. Their transcriptome was monitored in different organs of unstressed plants and in shoots in response to herbicides, UV-B radiation, endogenous stress hormones, and pathogen infection. A principal component analysis based on the transcription of these effector gene families defined distinct responses and crosstalk. Methyl jasmonate and ethylene treatments were separated from a group combining reactions towards two sulfonylurea herbicides, salicylate and an avirulent strain of Pseudomonas syringae pv. tomato. The responses to the herbicide bromoxynil and UV-B radiation were distinct from both groups. In addition, these analyses pinpointed individual effector genes indicating their role in these stress responses. A small group of genes was diagnostic in differentiating the response to two herbicide classes used. Interestingly, a subset of genes induced by $P$. syringae was not responsive to the applied stress hormones. Small groups of comprehensively induced effector genes indicate common defense strategies. Furthermore, homologous members within branches of these effector gene families displayed differential expression patterns either in both organs or during stress responses arguing for their non-redundant functions.
\end{abstract}

\footnotetext{
^ Supplementary material is available at: www.gsf.de/Forschung/Institute/biop.phtml/papers/Glombitza.
} 


\section{Introduction}

Plants feature an enormous variety of small organic, secondary metabolites, which possess diverse protective, defensive or signaling functions. Accordingly, many enzyme activities encoded by large gene families are involved in the biosynthesis, modification and compartmentation of these compounds. These gene families are assumed to have evolved to provide a broad diversification of similar biochemical reactions and flexibility of plant responses to different environmental conditions (Pichersky and Gang, 2000). Our laboratories are aiming at elucidating the function of gene families related to plant secondary metabolism, in particular with respect to their role as effector genes at the end of signaling cascades, which act in plant xenobiotic metabolism and pathogen defense. This study is focused on analyzing the transcriptomes of four gene families that are involved in different, biochemical reactions: oxidation by cytochrome P450 monooxygenases (CYP), conjugation with UDP-activated carbohydrates by secondary metabolite glycosyltransferases (UGT), conjugation with the tripeptide glutathione by glutathione transferases (GST), and eventually compartmentation via ATP-binding-cassette transporters (ABC transporters). Importantly, these enzyme classes are often acting consecutively in the synthesis and processing of secondary compounds and in detoxification reactions (Sandermann, 1994; Coleman et al., 1997; Jones and Vogt, 2001; Martinoia et al., 2002; Wagner et al., 2002).

CYP genes form one of the largest families with 272 genes annotated in Arabidopsis (WerckReichhart et al., 2002). Catalytic functions of CYPs are extremely diverse and usually result from the activation of molecular oxygen and insertion of one oxygen atom into a lipophilic substrate (Mansuy, 1998; Werck-Reichhart et al., 2002). Plant CYPs are involved in the synthesis of precursors of polymers, pigments, signaling and defense molecules and the hydroxylation or dealkylation of exogenously applied compounds (Chapple, 1998; Kahn and Durst, 2000; WerckReichhart et al., 2002; Schuler and Werck-Reichhart, 2003). CYPs are defined by a common structural fold and only three strictly conserved amino acids (Graham and Peterson, 1999; WerckReichhart et al., 2002). Sequence identity among plant CYPs ranges from below $20 \%$ to higher than $95 \%$ in highly duplicated sub-families forming clusters of up to 13 genes. By far the largest CYP clade is referred to as plant specific class A including mainly enzymes of secondary metabolism. Four to six other clades, referred to as NonA CYPs, are related to animal or microbial enzymes involved in lipid, sterol or isoprenoid metabolism (Werck-Reichhart et al., 2002). The function of more than $80 \%$ of the Arabidopsis CYP genes is unknown.

UGTs transfer carbohydrate residues onto small organic compounds to regulate their activity, toxicity or amenability to transport. Many of these compounds such as phytoalexins, cell wall precursors and plant hormones are important for plant defense, cellular homeostasis and signaling. UGTs, which are defined by a conserved domain in their C-terminal region, constitute a large gene family of up to 120 members including eight pseudogenes annotated in A. thaliana Columbia (Paquette et al., 2003). Phylogenetic alignment splits the $A$. thaliana UGTs into 14 subgroups ( $\mathrm{Li}$ et al., 2001). There is only limited information on the function of individual UGTs. Systematic as well as focused analyses of the substrate properties have been initiated (Milkowski et al., 2000; Jackson et al., 2001; Lim et al., 2001, 2002; Jones et al., 2003). UGTs may display a reduced substrate specificity and rather be regioselective accepting certain chemical substructures (Jones and Vogt, 2001). Importantly, UGTs with activity towards xenobiotic model compounds, which may interfere with endogenous substrates, have been described for recombinant Arabidopsis enzymes (Loutre et al., 2003; Messner et al., 2003).

Similarly to UGTs, GSTs have been implicated in the detoxification of endogenous and xenobiotic compounds and in plant secondary metabolism (Marrs, 1996; Edwards et al., 2000). GSTs are a family of multifunctional, dimeric enzymes that catalyze the conjugation of the tripeptide glutathione to a large variety of lipophilic compounds. Plant GSTs are also encoded by large and diverse gene families. The 47 Arabidopsis GSTs are divided on the basis of sequence similarity into the phi, tau, theta and zeta classes (Edwards et al., 2000; Dixon et al., 2002; Wagner et al., 2002). A fifth class of GST-like genes (lambda), which does not possess glutathione transferase activity (Dixon et al., 2002), was not included in this study. For a 
few members, roles in herbicide detoxification or development have been demonstrated (Marrs, 1996; Edwards and Dixon, 2000; Smith et al., 2003). Phi and tau GSTs catalyze the glutathionetagging of secondary metabolites including phytoalexins and isothiocyanates, function as glutathione peroxidases or they have non-catalytic roles (Edwards et al., 2000; Dixon et al., 2002). Some GSTs appear to have roles as hormone- or flavonol-binding proteins (Marrs, 1996; Gonneau et al. 1998; Smith et al., 2003), as components of UVinducible cell signaling pathways (Loyall et al., 2000 ) or as potential regulators of apoptosis (Kampranis et al., 2000; for review: Dixon et al., 2002). Zeta GSTs catalyze an important glutathione-dependent isomerization step in the catabolism of tyrosine (Dixon et al., 2000). Theta GSTs may be mainly active as glutathione peroxidases reducing organic hydroperoxides produced during oxidative stress (Edwards et al., 2000; Wagner et al., 2002).

Because of the important nature of glutathionedependent reactions in plant stress responses a complete set of additional glutathione-utilizing enzymes was included in this study: eight glutathione peroxidases $(G P X)$, six glyoxalases $(G L X)$ and two glutathione reductases $(G R)$. GPXs catalyze the GSH-dependent reduction of hydrogen peroxide and organic hydroperoxides. Two consecutive reactions catalyzed by GLXI and GLXII convert 2-oxoaldehydes, such as methylglyoxal, into the corresponding 2-hydroxy acids via a glutathionated intermediate (Thornalley, 1990). GRs catalyze the conversion of oxidized to reduced glutathione and play a major role in maintaining the reduced to oxidized glutathione balance (Noctor et al., 2002).

Eventually, $\mathrm{ABC}$ transporters are involved in compartmentation of endogenous metabolites or catabolites and in detoxification of xenobiotic conjugates. They are characterized by the presence of specific transmembrane and signature ATPbinding cassette domains. Arabidopsis harbors 105 predicted members (Martinoia et al., 2002). Fiftyfour members are full-size transporters containing two ATPase and two transmembrane domains each. These include 15 multidrug resistance related proteins (MRPs), 15 pleiotropic drug resistance proteins (PDRs) and 22 P-glycoproteins (PGPs). $\mathrm{ABC} 1$ homolog $(A O H I)$ and peroxisomal $\mathrm{ABC}$ transporter homolog $(P M P)$ are distinct full-size members. A few members have been localized to different membranes. MRP2 was inserted in the tonoplast, whereas PGP and PDR members were located to the plasma membrane (for review: Davies and Coleman, 2000; Sánchez-Fernández et al., 2001; Martinoia et al., 2002).

Some information is available on the transcription of these gene families. Several genes were shown to be transcriptionally activated by various stresses in agreement with their postulated function in stress protection. The stresses included exposure to ozone, hydrogen peroxide, signaling molecules, heavy metals, heat shock, dehydration, wounding, biotic elicitors and microbial infection (Marrs, 1996; Mullineaux et al., 1998; Jackson et al., 2001, 2002; Sánchez-Fernández et al., 2001; Kolukisaoglu et al., 2002; Mazel and Levine, 2002;

Table 1. Genes differentially responsive to sulfonylurea herbicides (PRI and PRO) and bromoxynil (BXN) in A. thaliana leaves. Numbers indicate expression ratios of treatments vs. controls $24 \mathrm{~h}$ after herbicide application (Materials and methods).

\begin{tabular}{lrrl}
\hline Gene & PRI & PRO & BXN \\
\hline Responsive to sulfonylurea & & & \\
CYP71B15 & 16.0 & $2.0^{\mathrm{a}}$ & $0.69^{\mathrm{b}}$ \\
CYP76C2 & 6.3 & 2.9 & $1.3^{\mathrm{b}}$ \\
CYP81D8 & 5.2 & 7.8 & $1.2^{\mathrm{b}}$ \\
GSTF2 & 6.6 & $2.0^{\mathrm{a}}$ & 0.59 \\
GSTF6 & 16.0 & 11.2 & 0.74 \\
GSTF7 & 5.2 & 16.0 & 0.67 \\
GSTU24 & 3.7 & 9.8 & n.d. \\
UGT73C5 & 2.9 & 6.9 & 1.5 \\
UGT74E2 & 12.5 & 7.4 & $\mathrm{n} . \mathrm{d}$. \\
UGT75B1 & 3.2 & 2.8 & 1.7 \\
UGT86A1 & 3.9 & 2.1 & $\mathrm{n} . \mathrm{d}$. \\
UGT87A2 & 4.0 & 2.9 & 1.5 \\
GR2 & 3.4 & 12.6 & 1.0 \\
MRP3 & 10.2 & 16.0 & 0.51 \\
PDR8 & 6.4 & 6.2 & $1.0^{\mathrm{b}}$ \\
Responsive to sulfonylurea and BXN & & \\
UGT74F2 & 8.0 & 4.0 & 4.3 \\
Responsive to BXN & & & \\
GPX3 & 0.65 & 0.54 & 2.5 \\
UGT75D1 & 0.86 & 1.0 & 3.7 \\
\hline
\end{tabular}

Significant inductions are displayed on white background, nonresponsive situations are highlighted in grey; n.d. not detected. ${ }^{a}$ Unambiguous induction assigned as 2.0, but strong difference in replicas (Supplementary Table 5; Materials and methods).

${ }^{\mathrm{b}}$ Mean expression value includes replicas where no expression was detected.

${ }^{\mathrm{c}}$ The highly homologous GSTF6 and GSTF7 may crosshybridize, however, independent analyses showed that both genes are responsive to primisulfuron (Table 4). 
A

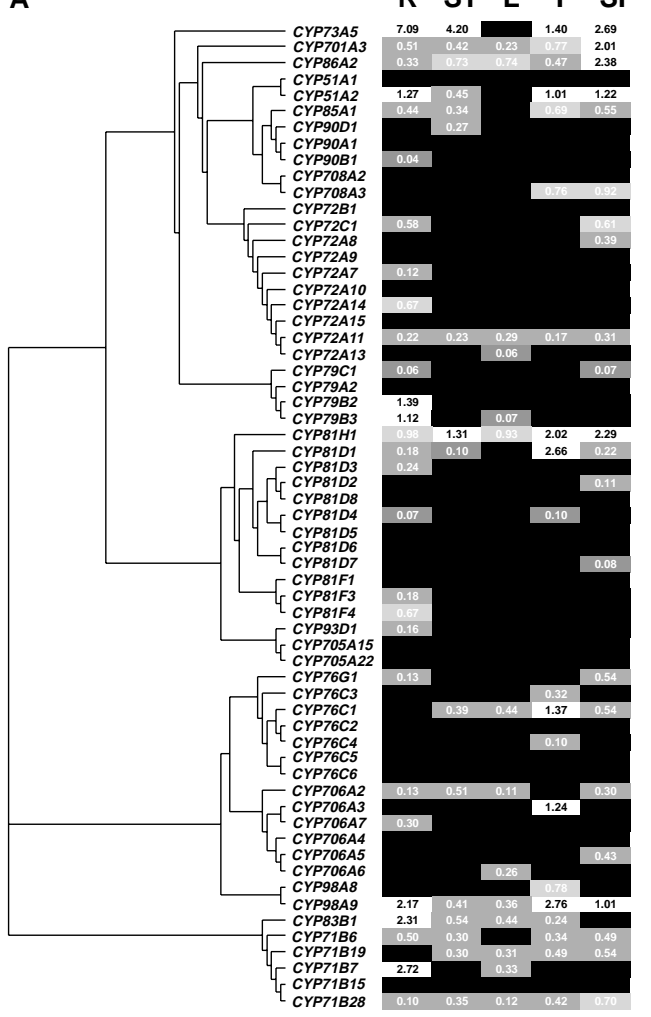

B

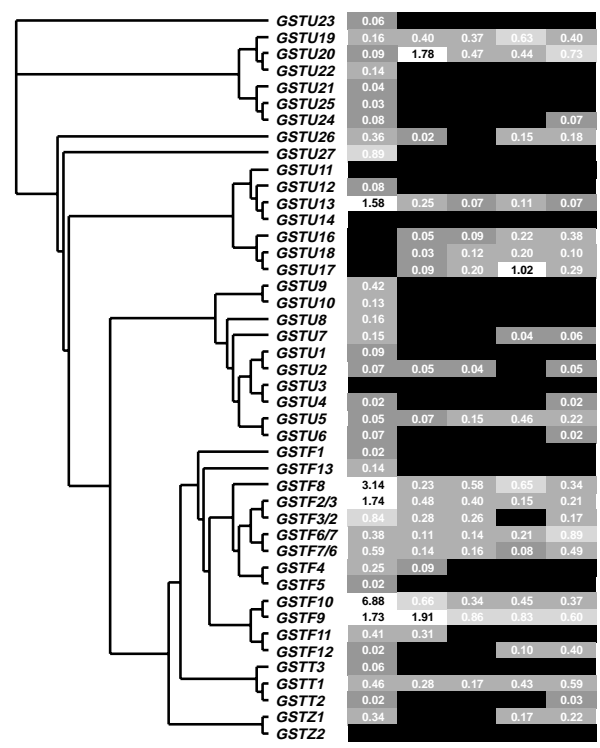

C

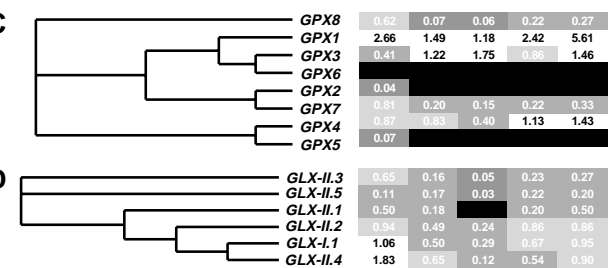

E

$\begin{array}{lllll}\text { R ST L I S } & \text { I }\end{array}$

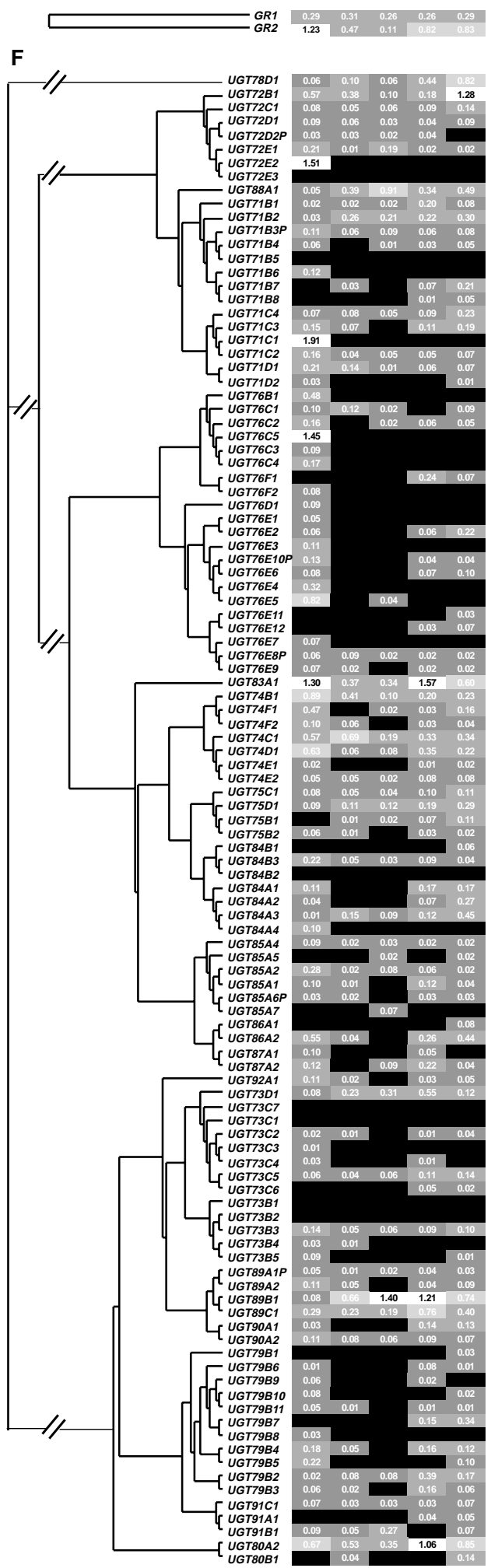




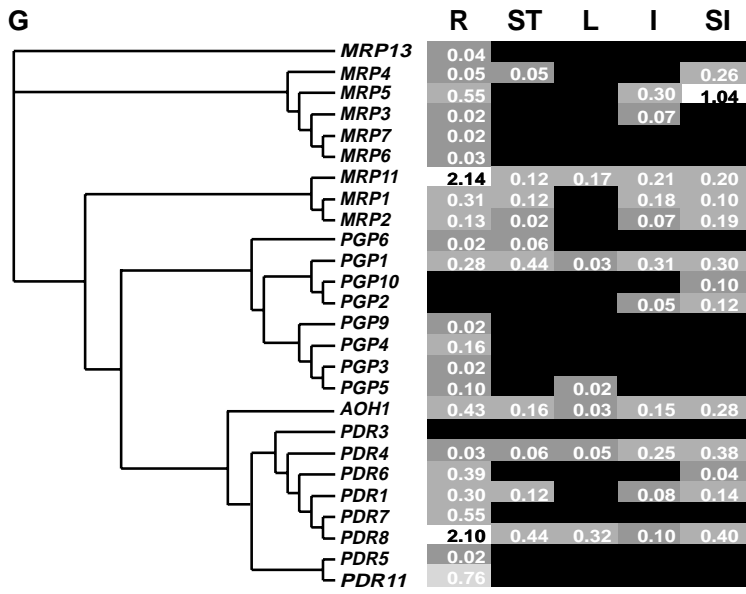

Figure 1. Organ-specific expression patterns. Expression in roots (R), stems (ST), leaves (L), inflorescences (I) and immature (green) siliques (SI) was examined for CYP (A) GST (B), GPX (C), GLX (D), GR (E), UGT (F) and ABC transporter (G) gene families in A. thaliana. Normalized gene expression values (Materials and methods) were highlighted by grey scales to visualize differences, black and white representing no detectable and highest expression levels, respectively. Due to size limitations the phylogenetic distances in the trees were shortened as indicated by double slashes; see Supplementary Figure 1 for the correct distances based on CLUSTAL W (Thompson et al., 1994) and TREEVIEW (Page, 1996) and Supplementary Table 3 for data of replicas.

van den Brûle and Smart, 2002; Wagner et al., 2002; Werck-Reichhart et al., 2002; Rodriguez Milla et al., 2003; Smith et al., 2003).

The present study was to initiate the comprehensive, functional analysis of these gene families aiming at identifying differential recruitment of individual members and groups of co-regulated effector genes in response to different abiotic and biotic stressors. A DNA array, named MetArray, for parallel expression profiling of 267 members of these gene families was established by designing gene-specific probes from their 3 '-regions.

\section{Results and discussion}

\section{Gene families and generation of probes}

Genes belonging to large families are often highly homologous within their coding regions. Therefore, target sequences for hybridization to genes associated with secondary metabolism were selected from their $3^{\prime}$-ends including untranslated regions. Probes were designed and checked using a semi-automatic, web-based algorithm (Affenzeller et al., in preparation). Briefly, the specificity of probes was first tested via BLAST analyses against the whole $A$. thaliana genome sequence. In addition, FASTA sequence comparisons with all predicted $A$. thaliana ORFs of the MIPS database including $500 \mathrm{nt}$ extensions at both ends were performed. This analyses were refined by considering the relative orientation of genes and experimental cDNA sequences. Nevertheless, in a few cases it was not possible to exclude any crossreactivity due to densely packed genes or due to the high homology of the genes, e.g. the pairs GSTF2/ GSTF3 and GSTF6/GSTF7. In agreement with Xu et al. (2001) probes exhibiting a homology of at most $70 \%$ over a stretch of $70 \mathrm{nt}$ were regarded as highly specific; a considerable cross-hybridization was indicated for probes with more than $85 \%$ homology over $100 \mathrm{nt}$ (Supplementary Table 1).

Genome-wide sets of gene-specific probes for 116 Arabidopsis UGTs including seven putative pseudogenes, all 47 GSTs, eight GPXs, six GLXs, and two GRs were designed. In addition, two subsets of Arabidopsis genes encoding CYP and $\mathrm{ABC}$ transporters were included. A group of 62 CYP genes was arbitrarily selected with the intention to include members fulfilling diverse criteria: known function, high EST frequency, A and Non-A type CYP genes, and a sample of genes belonging to highly duplicated subfamilies. Twenty-six full-length $\mathrm{ABC}$ transporters were selected on the basis of members annotated at the beginning of this project. This set contained nine MRP-, eight PGP-, eight PDR-type genes, and the single copy AOH1. The phylogenetic relationships of the gene families represented on the MetArray are shown in Figure 1.

Information concerning all probe sequences, bioinformatic analyses and specificity can be accessed at mips.gsf.de/proj/thal/primerDesign/index.html and as a supplementary table (Supplementary Table 1), where a possible cross-reactivity is discussed for thirty-five out of 267 probes. Thus, any potential conflict is pinpointed to guide a targeted examination by an independent technique.

\section{Organ distribution of transcripts}

The MetArray was used to obtain comprehensive information about the organ expression patterns of these gene families in roots, rosette leaves, 
stems, inflorescences and immature siliques. This knowledge was to provide a framework for assessing potential redundancies and functions of these genes in different organs.

Ubiquitously and often highly expressed genes were detected among all gene families (Figure 1AG). Most remarkable was the high and constitutive expression of most glyoxalases, glutathione reductases and glutathione peroxidases as well as many glutathione transferases (Figure 1C-E). Among the glutathione peroxidases, GPXI and $G P X 3$ showed the highest transcription in all organs, whereas the closely related GPX6 could not be detected in any tissue (Figure 1C). All glyoxalases except $G L X-I I .1$ were expressed at a high level in all organs (Figure 1D). A few out of 47 Arabidopsis glutathione transferases were highly and ubiquitously transcribed. This mostly pertained to members from closely related subgroups, such as the tau GSTs GSTU5, GSTU13, GSTU19, GSTU20 and the phi members GSTF2, GSTF8, GSTF9, and GSTF10. In contrast, transcripts of highly related other members were not detected or differentially expressed (Figure 1B). Among the CYP, UGT and ABC transporter genes only a few members were constitutively expressed at a higher level, e.g. CYP73A5, CYP51A2, CYP81H1, CYP98A9, UGT72B1, UGT74C1, UGT80A2, UGT83A1, UGT89B1, MRP11 or PDR8. These high and wide-spread expression patterns might indicate constitutive functions. Nevertheless, it was interesting to note that a few of these genes were further enhanced in response to different stimuli, e.g. GPX1, GPX3, GPX4, GR2, GSTF2, GSTF10, GSTU19, UGT80A2, CYP71B28, CYP73A5, or PDR8 (see below; Tables 1-3).

Highly related members of the large UGT subgroup L (Ross et al., 2001; Figure 1F: UGT74B1UGT84A4) showed widely overlapping expression patterns, which could indicate redundant functions. However, using recombinant enzymes several of these $U G T \mathrm{~s}$ had been shown to exhibit differential substrate preferences (Jackson et al., 2001; Lim et al., 2001, 2002). Similarly, the overlapping expression patterns of GSTU16/GSTU17/GSTU18, of $G P X 1 / G P X 3$ or of $G R 1 / G R 2$ (Figure 1B, C and $E)$ would be in agreement with redundant functions. However, they differed in their stress responsiveness (see below). On the other hand, several genes belonging to highly related branches displayed differential expression patterns indicating non- redundant functions, e.g. $U G T 71 C, U G T 76 E$, and $U G T 79 B$ branches, GSTF11/GSTF12, theta GST and several tau GST subgroups, GPX2/GPX7, or PDR1/PDR6/PDR7/PDR8.

CYP genes seemed to have a much stronger on/ off control than most other genes (Figure 1A). This might reflect a tighter control of gene expression, possibly related to the higher substrate specificity and their functions as rate limiting steps in many pathways. Among the other gene families studied there were only a few examples that showed similar control. Restricted expression patterns were observed for $U G T 71 C 1, U G T 72 E 2$, members of the $U G T 76 B$ subgroup, several GSTU members, or PDR7 and PDR11 (Figure 1).

At least in a qualitative manner, the MetArray expression patterns matched most previously reported data by Northern, RT-PCR, or promoterreporter analyses of single CYP genes (Bell-Lelong et al., 1997; Mizutani et al., 1998), of genes encoding UGTs and glutathione-dependent enzymes (Warnecke et al., 1997; Jackson et al., 2001; Jones et al., 2003; Loutre et al., 2003; Rodriguez Milla et al., 2003), or groups of ABC transporter genes (Kolukisaoglu et al., 2002; van den Brûle and Smart, 2002). A compilation of examples are provided as supplementary information (Supplementary Table 2). However, when comparing the MetArray data with other information it is important to bear in mind that developmental and environmental differences as well as a lower sensitivity of the MetArray compared to RT-PCR may contribute to discrepancies. A technical difference could account for the observation that the array expression levels in leaves tended to be lower. A high amount of photosynthetic gene mRNAs may considerably dilute total transcripts and thereby it may affect hybridization in a different way than other analyses (Materials and methods).

In summary, the observed expression patterns support the functional significance and diversity provided by these large gene families and, consequently, they argue against truly redundant functions within these enlarged gene families as long as complete branches had been investigated. In addition, co-expression patterns of genes from different families matched their known biochemical functions indicating a respective functional relation in planta. The constitutive expression of CYP51A2, which encodes a $14 \alpha$-demethylase having a housekeeping role in the biosynthesis of 
Table 2. Genes responsive to ethylene (ETH), methyl jasmonate (MeJA), salicylic acid (SA) and bacterial infection (PSavir). Numbers indicate expression ratios after treatments vs. controls (Materials and methods).

\begin{tabular}{lrrrr}
\hline Gene & ETH & MeJA & SA & PSavir \\
\hline Coordinate induction & & & & \\
CYP71B15 & 11.4 & 13.6 & 6.7 & 16.0 \\
GSTF2 & 4.9 & 4.5 & 2.7 & 15.1 \\
SSTF6 $^{\mathrm{a}}$ & 3.3 & 2.4 & 6.9 & 16.0 \\
GSTF7 $^{\mathrm{a}}$ & 2.3 & 1.6 & 3.3 & 9.7
\end{tabular}

Responsive to PSavir/SA vs. ETH/MeJA

$\begin{array}{lllll}C Y P 71 B 28 & 0.20 & 0.26 & 5.4 & 3.6 \\ \text { GPX7 } & 0.88 & 0.40 & 3.1 & 7.0 \\ U G T 74 F 2^{\mathrm{b}} & \text { n.c. } & 1.6 & 1.9^{\mathrm{b}} & 4.2 \\ \text { MRP3 } & 1.6 & 0.69 & 2.4 & 5.4 \\ U G T 71 C 3^{\mathrm{c}} & 2.3 & 2.0 & 0.81 & 0.87^{\mathrm{d}} \\ U G T 85 A 5 & 0.31 & 0.46 & 0.80 & \text { n.d. } \\ \text { AOH1 } & 3.0 & 2.3 & 1.5 & 1.2^{\mathrm{d}}\end{array}$

Responsive to PSavir and ETH/MeJA

\begin{tabular}{lllll} 
CYP72A8 & 4.9 & $1.7^{\mathrm{d}}$ & $1.2^{\mathrm{d}}$ & 4.2 \\
GSTZ1 & 2.6 & 1.3 & 1.6 & 4.3 \\
GSTF10 & 1.9 & 2.7 & 1.1 & 2.3 \\
Responsive to & PSavir, & \multicolumn{4}{c}{ but } & not & to & ETH, MeJA, SA & \\
CYP73A5 & 1.1 & 0.88 & 1.5 & 2.9 \\
CYP76C6 & 0.58 & 0.85 & 1.6 & 4.3 \\
CYP79B2 & n.d. & n.d. & n.d. & 16.0 \\
CYP83B1 & 1.5 & 1.9 & 1.5 & 2.4 \\
GSTU16 & 1.6 & 0.55 & 1.3 & 3.5 \\
GSTU19 & 1.8 & 1.1 & 1.3 & 9.2 \\
GLX-II.3 & 1.1 & 0.92 & 0.73 & 4.6 \\
GPX1 & 1.2 & 1.2 & 1.5 & 14.6 \\
GPX4 & 1.4 & 0.91 & 1.4 & 3.9 \\
UGT80A2 & 1.1 & 0.75 & 0.83 & 3.1 \\
UGT85A1 & 1.6 & 0.82 & 0.78 & 8.1 \\
UGT87A2 & 1.9 & 1.2 & 1.9 & 5.3 \\
UGT89B1 & 1.6 & 0.64 & 0.95 & 0.39 \\
MRP5 & n.d. & n.d. & n.d. & 4.2 \\
PDR8 & 1.3 & 1.5 & 1.4 & 8.7 \\
\cline { 1 - 3 } & & & &
\end{tabular}

Significant inductions are displayed on white background and reductions on dark grey background; non-responsive situations are highlighted in grey.

n.d. not detected; n.c. not clear, conflicting data in replicas (Supplementary Table 6; Materials and methods).

${ }^{a}$ The highly homologous GSTF6 and GSTF7 may crosshybridize, however their induction was confirmed independently (Table 4).

${ }^{\mathrm{b}}$ The weak response to SA was confirmed by RT-PCR (Table 4). ${ }^{\mathrm{c}}$ Probe may cross-hybridize with homologous member (UGT71C4), which showed similar reaction.

${ }^{\mathrm{d}}$ Mean expression value includes replicas, where no expression was detected.

steroids, was paralleled by the expression of UGT80A2, which glucosylates sterols in vitro (Figure 1A and F; Warnecke et al., 1997; WerckReichhart et al., 2002).
Table 3. Correlated responses to sulfonylurea herbicides (PRI and PRO) and bacterial infection (PSavir). Numbers indicate expression ratios of treatments vs. controls (Materials and methods).

\begin{tabular}{|c|c|c|c|c|}
\hline Gene & PRI & PRO & PSavir & SA \\
\hline \multicolumn{5}{|c|}{ Comprehensively induced genes } \\
\hline CYP71B15 & 16.0 & $2.0^{\mathrm{a}}$ & 16.0 & 6.7 \\
\hline СYР72A8 & 5.9 & 2.0 & 4.2 & $1.2^{\mathrm{b}}$ \\
\hline GSTF2 & 6.6 & $2.0^{\mathrm{a}}$ & 15.1 & 2.7 \\
\hline$G S T F 6^{\mathrm{C}}$ & 16.0 & 11.2 & 16.0 & 6.9 \\
\hline$G S T F 7^{\mathrm{c}}$ & 5.2 & 16.0 & 9.7 & 3.3 \\
\hline GSTZ1 & 9.9 & n.d. & 4.3 & 1.6 \\
\hline$M R P 3$ & 10.2 & 16.0 & 5.4 & 2.4 \\
\hline \multicolumn{5}{|c|}{ Co-induction by sulfonylurea and PSavir } \\
\hline$C Y P 71 B 19^{\mathrm{d}}$ & 8.2 & 0.79 & $2.0^{\mathrm{b}}$ & 1.8 \\
\hline CYP73A5 & 1.0 & 3.2 & 2.9 & 1.5 \\
\hline CYP81D8 & 5.2 & 7.8 & 2.2 & 0.90 \\
\hline GSTU4 & 4.3 & n.d. & 2.8 & 0.90 \\
\hline GSTU16 & 2.1 & $0.73^{\mathrm{b}}$ & 3.5 & 1.3 \\
\hline GSTU19 & 2.0 & 10.9 & 9.2 & 1.3 \\
\hline$G L X-I I .3$ & 2.9 & n.d. & 4.6 & 0.73 \\
\hline$G P X 1$ & 16.0 & n.c. & 14.6 & 1.5 \\
\hline GPX4 & 2.0 & 3.1 & 3.9 & 1.4 \\
\hline$G P X 7$ & 3.5 & n.d. & 7.0 & 3.1 \\
\hline$U G T 74 F 2^{\mathrm{e}}$ & 8.0 & 4.0 & 4.2 & $1.9^{\mathrm{e}}$ \\
\hline UGT76B1 & 6.4 & n.d. & 7.6 & 1.5 \\
\hline UGT87A2 & 4.0 & 2.9 & 5.3 & 1.9 \\
\hline MRP5 & 3.8 & n.d. & 4.2 & n.d. \\
\hline$P D R 8$ & 6.4 & 6.2 & 8.7 & 1.4 \\
\hline
\end{tabular}

Significant inductions are displayed on white background, nonresponsive situations are highlighted in grey.

n.d. not detected; n.c. not clear due to conflicting data in replicas.

${ }^{\mathrm{a}}$ Unambiguous induction assigned as 2.0 , but strong difference in replicas (Supplementary Tables 5 and 6; Materials and methods);

${ }^{\mathrm{b}}$ Mean expression value includes replicas, where no expression was detected.

${ }^{\mathrm{c}}$ The highly homologous GSTF6 and GSTF7 may crosshybridize, however, their induction was confirmed independently (Table 4).

${ }^{\mathrm{d}}$ Probe may cross-react with closely related CYP71B16, $C Y P 71 B 17$, and $C Y P 71 B 20$.

${ }^{\mathrm{e}}$ The weak response to SA was confirmed by RT-PCR (Table 4).

Principal component analysis of transcriptional responses to chemical, biological and physical challenges

Gene families acting in secondary metabolism may be involved as effector genes in response to diverse environmental cues. Therefore, the MetArray was used to monitor transcriptional changes in response to diverse abiotic and biotic stimuli and to elucidate both stress-specific and overlapping responses. The analyses were focused on the reaction 
<smiles>COC(=O)c1ccccc1S(=O)(=O)[O-]</smiles>

B<smiles>COc1cc(C)nc(NC(=O)[N+](=O)[O-])n1</smiles>

C

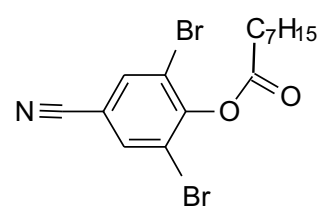

Figure 2. Herbicides sprayed in sublethal doses onto threeweek-old Arabidopsis plants. Primisulfuron (A), prosulfuron (B), and bromoxynil octanoate (C).

of $A$. thaliana leaves $24 \mathrm{~h}$ after application of the stimuli. As chemical stressors two different classes of herbicides were chosen (Figure 2). Bromoxynil $(\mathrm{BXN})$, a photosystem II targeting herbicide, and two different sulfonylurea herbicides, primisulfuron (PRI) and prosulfuron (PRO), interfering with the biosynthesis of branched amino acids, were sprayed at sublethal doses. Continuous UV-B irradiation (UVB) was used as a physical stressor provoking oxidative damage and defense reactions (Surplus et al., 1998). Infection by the avirulent bacterial pathogen, Pseudomonas syringae pv. tomato DC3000 (avrRpt2) [PSavir] was included as a biological stressor. Finally, plants were treated with the three plant stress hormones salicylic acid [SA], ethylene [ETH], and methyl jasmonate [MeJA] (Dong, 1998; Kunkel and Brooks, 2002). Only those genes were kept for further analyses, whose expression was detected in at least three treatments or showed two-fold or higher changes in at least one condition. This measure reduced the number of genes from 267 to 135 (Supplementary Table 4). The complete set of data including replica experiments can be accessed as supplementary data (Supplementary Tables 5 and 6).

To identify differences between and correlations among the transcriptional responses to the various stimuli the expression data were subjected to a principal component analysis (PCA; Figure 3). Transcriptional reactions after treatment with the signal molecules MeJA and ETH gave one highly correlated group. Responses to SA were associated with an independent group that included genes induced by the avirulent $P$. syringae [PSavir]. Interestingly, this group also contained genes responsive to two different sulfonylurea herbicides, primisulfuron and prosulfuron. The response patterns established by treatment with another herbicide, bromoxynil or UV-B radiation were different from both groups (Figure 3). Although the correlation of UVB and bromoxynil was less significant in the PCA, it could indicate a common defense strategy against oxidative damage, which is provoked by both stressors. The UVB experiment, however, differed from all other treatments because it was designed to analyze the long-term effects on plants grown in the presence of UV-B (Götz et al., in preparation). Since the CYP and ABC trans-

Table 4. RT-PCR analyses of individual CYP, GST, UGT, and ABC transporter genes.

\begin{tabular}{|c|c|c|c|c|c|c|c|c|}
\hline \multirow[t]{2}{*}{ Gene } & \multicolumn{2}{|l|}{ PRI } & \multicolumn{2}{|l|}{ BXN } & \multicolumn{2}{|l|}{ PSavir } & \multicolumn{2}{|l|}{ SA } \\
\hline & Array & RT-PCR & Array & RT-PCR & Array & RT-PCR & Array & RT-PCR \\
\hline CYP71B15 & 16 & $34.5 \pm 2.1$ & n.d. & $0.5 \pm 0.2$ & 16 & $13.7 \pm 3.5$ & - & - \\
\hline CYР72A8 & $5.9 \pm 3.0$ & $3.4 \pm 0.3$ & n.d. & $0.5 \pm 0.1$ & $4.2 \pm 2.4$ & $2.6 \pm 0.2$ & - & - \\
\hline GSTF2 & $6.6 \pm 1.3$ & $3.0 \pm 2.0$ & $0.6 \pm 0.2$ & $1.1 \pm 0.1$ & $15.1 \pm 17.5$ & $3.6 \pm 1.5$ & $2.7 \pm 1.5$ & $2.8 \pm 1.5$ \\
\hline GSTF3 & $4.8 \pm 0.9$ & n.d. & $0.7 \pm 0.1$ & n.d. & $6.1 \pm 1.6$ & n.d. & $3.0 \pm 2.1$ & n.d. \\
\hline GSTF6 & 16 & $1.8 \pm 0.7$ & $0.7 \pm 0.1$ & $0.4 \pm 0.2$ & 16 & $2.7 \pm 0.5$ & $6.9 \pm 7.8$ & $1.9 \pm 0.1$ \\
\hline GSTF7 & $5.2 \pm 4.1$ & $3.0 \pm 0.8$ & $0.7 \pm 0.3$ & $0.7 \pm 0.5$ & $9.7 \pm 6.3$ & $4.9 \pm 2.5$ & $3.3 \pm 1.8$ & $2.4 \pm 0.7$ \\
\hline$U G T 74 F 2$ & $7.9 \pm 3.9$ & $4.4 \pm 1.3$ & $4.3 \pm 3.3$ & $1.6 \pm 0.0$ & $4.2 \pm 2.1$ & $2.7 \pm 0.1$ & $1.9 \pm 1.1$ & $2.4 \pm 0.1$ \\
\hline$M R P 3$ & $10.2 \pm 8.4$ & $2.7 \pm 0.5$ & $0.5 \pm 0.6$ & $0.8 \pm 0.2$ & $5.4 \pm 3.1$ & $2.1 \pm 0.2$ & $2.4 \pm 0.9$ & $1.9 \pm 0.1$ \\
\hline
\end{tabular}

Verifications by semi-quantitative RT-PCR analyses were compared to inductions determined by MetArray analyses. Standard deviations are indicated. As for statistical analyses, high array induction values were limited to 16 (Materials and methods); n.d. not detected. See also Supplementary Table 7 for additional data. 


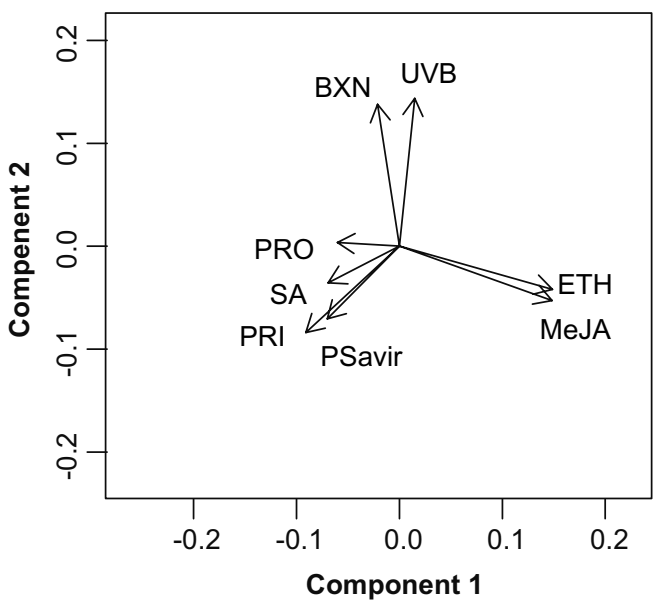

Figure 3. Principal component analysis. The statistical analysis was based on a subset of 135 genes, which responded at least in one treatment with a two-fold change in expression; the two components reflect $45.7 \%$ of the total variability of the data set (Materials and methods).

porter gene members were not included as full genome sets, it is important to note that these three major groups in the PCA were retained when eliminating either one of the partial gene families or both families from PCA (Supplementary Figure 3). Thus, the identified correlations are not biased by selecting these subgroups.

The separation of the ETH and MeJA response from the reaction to PSavir and SA was not surprising per se. Several genetic analyses and gene expression studies revealed a mutually antagonistic nature of the SA-dependent and jasmonate- or ethylene-dependent defense pathways but also substantial overlap between these different signaling pathways (for review: Kunkel and Brooks, 2002). However, it is important to emphasize that the correlations demonstrated here were based on a small set of effector gene families related to secondary metabolism lacking classical marker genes for these pathways like pathogenesis-related proteins or components of signaling cascades (Dong, 1998; Kunkel and Brooks, 2002). The enormous genetic diversity of secondary metabolism may endow the plant with the ability to recruit differential consortia of effector genes in response to various stimuli. Nevertheless, responses to different biotic and abiotic stimuli may also converge as indicated by the co-induction of genes by several inputs (see below).

A subset of genes was extracted from the PCA that most significantly contributed to the differ-

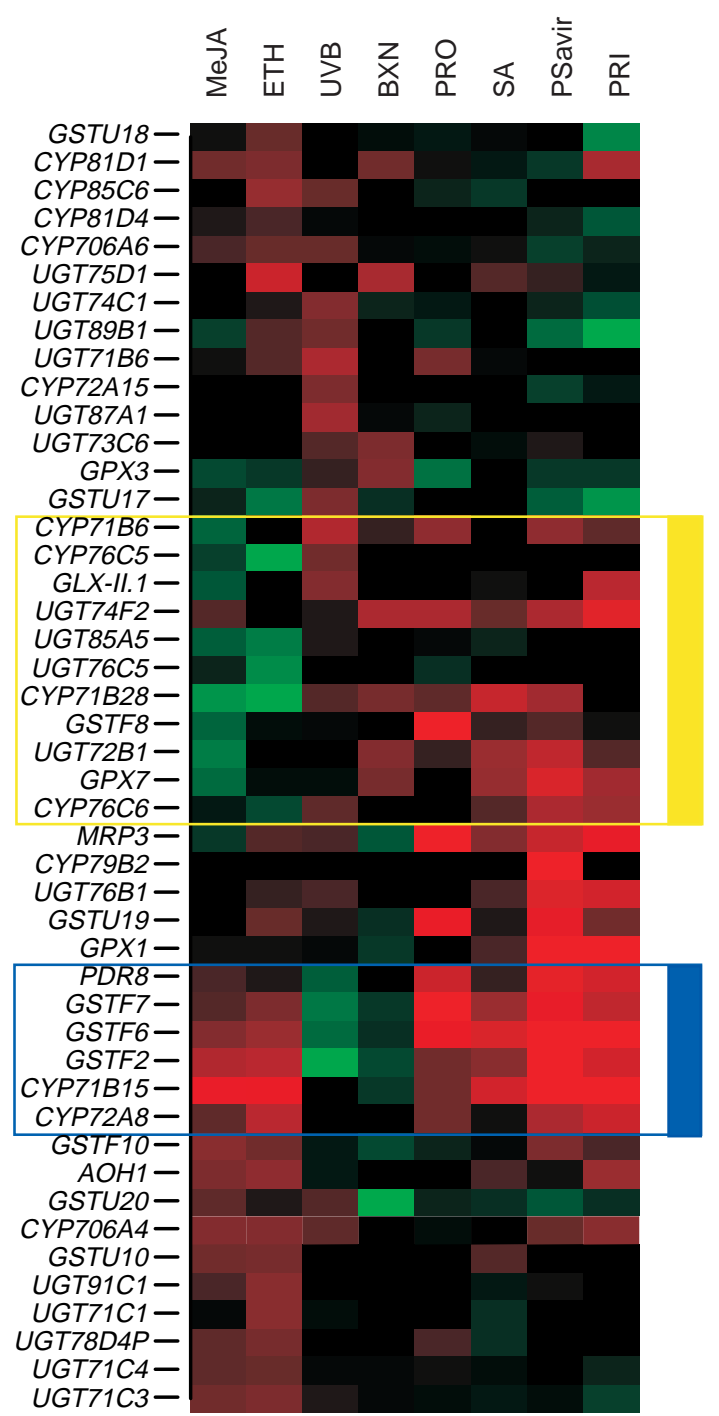

Figure 4. Expression patterns in response to herbicides (BXN, PRI, PRO), plant stress hormones (ETH, MeJA, SA), UV-B irradiation (UVB) and pathogen infection (PSavir). The compilation is based on a principal component analysis. 46 out of 135 genes showing the highest variance in distinguishing transcriptional responses are displayed (Materials and methods). Color-coding of the original, log2-transformed expression ratios (treatment vs. control) ranges from intense red (larger than 2) to intense green (lower than -2), black meaning no change (ratio 0). For numerical data and individual expression values see Supplementary Tables 5 and 6.

entiation or association of stress responses, respectively (Figure 4; Materials and methods). Among these genes two small subgroups were coinduced by several stimuli indicating their involvement in comprehensive reactions. Both groups identify effector genes that are likely to be 
activated by converging, yet differentiating defense pathways.

One group comprised genes that were not induced or even repressed by ethylene or methyl jasmonate but activated by several other stimuli (Figure 4; yellow group). This group pinpointed several distinct members of the CYP and UGT families as well as GLX-II.1, GSTF8, and GPX7. All genes except the putative salicylate-glucosyltransferase UGT74F2 (Lim et al., 2002) encoded enzymes of so far unknown biochemical or physiological functions. Another group combined genes that were widely induced by sulfonylurea herbicides, pathogen inoculation and the three stress hormones SA, MeJA and ETH. In contrast, no enhancement was found after BXN application and UV-B irradiation (Figure 4, blue group). In addition to $C Y P 72 A 8$ and $P D R 8$, this group also contained CYP71B15, GSTF2, GSTF6, and GSTF7. The latter genes are distinct members of subfamilies that were found to be associated with the yellow group. Therefore, these stress-responsive expression patterns do clearly indicate differential functions fulfilled by these homologous members in specific contexts.

The induction of GSTF2 and of the homologous GSTF6 and GSTF7 by several stress signals had been already described (Maleck et al., 2000: ERD11=GSTF6, GST11=GSTF7; Wagner et al., 2002). Parallel RT-PCR analyses revealed that both GSTF6 and GSTF7 were regulated in a similar way, whereas only GSTF2, but not the homologous GSTF3, was responsive to multiple stimuli (Table 4). Interestingly, Smith et al. (2003) demonstrated that GSTF2 binds flavonols and might participate in the regulation of auxin transport. The functional relationship between its suggested roles in development and in stress responses are yet to be elucidated. CYP71B15 that also fell into this group encodes a step in the biosynthesis of camalexin. Thus, elevation of this phytoalexin could be part of a general stress response. The inclusion of $C Y P 72 A 8$ and the $\mathrm{ABC}$ transporter $P D R 8$ within this group provided a first hint to their multiple involvements in plant stress responses.

\section{Differential response to herbicides}

As indicated by the PCA the responses to two sulfonylurea compounds, primisulfuron and pro- sulfuron, were clearly distinct from the reaction to bromoxynil. A number of genes comprising members of all families were specifically induced by the two herbicide classes (Table 1; Supplementary Table 5).

Several genes were induced by primisulfuron and prosulfuron but not responsive to bromoxynil. With the exception of the specifically induced GSTU24, UGT74E2, UGT75B1, and UGT86A1 (see below), all other genes of this group were also responsive to other stressors. GR2 was activated by sulfonylureas in contrast to its isoform $G R I$ that is also expressed in leaves (Table 1, Figure $1 \mathrm{E}$ ). Sulfonylureas enhanced the transcription of $C Y P 71 B 15$, involved in phytoalexin biosynthesis, and CYP76C2 (Table 1). Both CYPs had been previously characterized as pathogen-inducible genes (Godiard et al., 1998; Zhou et al., 1999). In addition to $C Y P 81 D 8, U G T 73 C 5$, and UGT87A2, which were not known to be stress-related, this group also contained the stress-responsive genes GSTF2, GSTF6, GSTF7 and PDR8 (Table 1; Figure 4). PDR-type ABC transporters might be involved in defense and detoxification, which had been indicated for three homologous members from other plant species (Smart and Fleming, 1996; Jasinski et al., 2001; Sasabe et al., 2002; van den Brûle et al., 2002). The known induction of the Arabidopsis ABC transporter MRP3 by sulfonylureas (Tommasini et al., 1997) was confirmed by this analysis.

Two genes were identified that are specifically induced by bromoxynil in comparison to sulfonylureas, the highly and ubiquitously expressed glutathione peroxidase GPX3 and the glucosyltransferase $U G T 75 D 1$. Neither GPX3 nor $U G T 75 D 1$ were responsive to treatment with the three stress hormones or pathogen infection (Supplementary Table 4). Interestingly, recombinant UGT75D1 was shown to glucosylate the xenobiotic compound 2,4,5-trichlorophenol (Messner et al., 2003). GPX3 could be specifically involved in antagonizing oxidative damage that occurred as a result of inhibition of photosystem electron transport by BXN. Interestingly, distinct GPX members were up-regulated by PSavir in both SA-dependent and SA-independent manners (Table 2; see below).

A single gene, $U G T 74 F 2$, was found to be coinduced by both chemical classes of herbicides as well as by pathogen treatment and SA application 
(Tables 1, 2, 4; Figure 4). Furthermore, its woundinducibility has been recently described by Cheong et al. (2002; gene AAB64024). In vitro studies using recombinant enzymes showed that UGT74F2 is able to glucosylate SA by preferentially forming its glucose ester (Lim et al., 2002). A highly related second enzyme, UGT74F1 that specifically catalyzes the formation of SA-2-O-glucoside in vitro was neither induced by BXN nor sulfonylureas (Supplementary Table 5). Thus, a specific pathway glucosylating SA might be induced by these herbicides. BXN is also an inhibitor of cinnamate 4hydroxylase that may trigger the accumulation of SA (Schalk et al., 1997; Schoch et al., 2002). Thereby, the induction of $U G T 74 F 2$ could be part of an SA detoxification mechanism.

Genes directly involved in the detoxification of these xenobiotic compounds may be included among the induced transcripts. In particular, transferase genes that are not responsive to other treatments may be good candidates. These include GSTU24, UGT74E2, UGT75B1 and UGT86A1 (Table 1; Supplementary Table 4). Especially, the role of the induced UGT genes deserves further investigation because glucosylation is known to be involved in the detoxification of both herbicide classes (Schaller et al., 1992; Kreuz and Martinoia, 1999). Recombinantly expressed UGT75B1 catalyzed the glucosylation of benzoic acid and hydroxyl-derivatives thereof (Lim et al., 2002).

In conclusion, this analysis defined two groups of genes that are suitable to distinguish the response to sulfonylurea compounds and bromoxynil. Individual effector genes from secondary metabolism were associated with reactions of the plant towards different classes of exogenous chemicals.

\section{Differential responses to plant stress hormones and bacterial infection}

Inoculation by the avirulent pathogen Pseudomonas syringae pv. tomato DC3000 (avrRpt2) induces SA-dependent gene expression in $A$. thaliana (Maleck et al., 2000). PCA showed that this correlation was also reflected at the level of effector gene families related to secondary metabolism. It was clearly distinct from the reaction to ETH and MeJA (Figure 3). The latter hormones are known to activate overlapping signaling pathways (Xu et al., 1994; Penninckx et al., 1998; Kunkel and Brooks, 2002).
The transcriptional changes of several genes were responsible for these correlations. The ABC transporter $M R P 3$, the putative salicylic acid glucosyltransferase $U G T 74 F 2$, and two genes with unknown roles, $C Y P 71 B 28$ and $G P X 7$, were activated by PSavir and SA in contrast to ETH and MeJA, which could even repress the expression of the two latter genes (Table 2). On the other hand, the expression of three genes with unknown functions, UGT71C3, UGT85A5 and AOH1 was altered by ETH and MeJA but non-responsive to SA or pathogen infection (Table 2).

However, a number of these effector genes exhibited other co-induction patterns. This provided further evidence for alternative crosstalks among defense signaling pathways (for review: Kunkel and Brooks, 2002) and identified effector genes as specific targets. First, CYP71B15, GSTF2, GSTF6, and GSTF7, which had been already identified as comprehensively induced effector genes, were coordinately enhanced (Table 2; Figure 4). Second, the Pseudomonas-responsive CYP72A8, GSTZ1 and GSTF10 were co-induced by either ETH or MeJA but not by SA (Table 2). Schenk et al. (2000) had previously described similar correlations among the different signaling pathways mostly based on known stressresponsive and signaling components. Importantly, this analysis pinpointed individual effector genes, which also reflected such responses and crosstalks.

Interestingly, this compilation revealed a large group of genes from all families that was specifically responsive to the PSavir. These genes indicated an induction or suppression by the bacterial pathogen that was independent from the response to the three stress hormones. Thara et al. (1999) had previously reported two tomato transcription factors that were induced by a virulent Pseudomonas strain independent of ETH, SA and jasmonate. Thus, independently mediated or obligatorily synergistic signaling pathways may exist. More than half of the genes within this group had no known physiological functions, such as e.g. CYP76C6, GSTU19, GPX4, UGT87A2, or PDR8. In vitro, UGT80A2 glucosylated sterols (Warnecke et al., 1997) and MRP5 was implicated in the regulation of ion fluxes (Gaedecke et al., 2001). However, a few genes of this group had known functions in plant defense: CYP73A5 encoding cinnamate 4-hydroxylase and CYP79B2 and 
CYP83B1, which are involved in the biosynthesis of indole glucosinolates (Bak et al., 2001; Mikkelsen et al., 2003). Using RT-PCR, Mikkelsen et al. (2003) could also demonstrate an induction of $C Y P 79 B 2$ by MeJA that was not detected by the array analysis.

Correlation of responses to sulfonylurea herbicides and Pseudomonas

PCA revealed an interesting association of transcriptional responses to sulfonylurea herbicides with Pseudomonas inoculation and SA treatment (Figure 3). Several comprehensively induced genes, CYP71B15, CYP72A8, GSTF2, GSTF6, GSTF7, GSTZ1, and MRP3 were contributing to this correlation (Table 3). A number of additional genes including members of all effector gene families specifically linked the responses to sulfonylureas and to the bacterial pathogen (Table 3). Interestingly, the majority of these genes had been already identified as PSavir-enhanced genes that were not induced by individual stress hormones (Tables 2 and 3).

Their co-induction suggested that they might exhibit overlapping roles in reactions to the biotic and specific abiotic stressors. CYP73A5 encodes cinnamate 4-hydroxylase as a key enzyme in the phenylpropanoid biosynthesis that may be either co-regulated with or dissociated from the response of other genes of this pathway (Bell-Lelong et al., 1997; Mizutani et al., 1997; Jin et al., 2000). The ubiquitously expressed GPXI (Figure 1C) had been shown to be responsive to oxidative and abiotic stresses (Sugimoto and Sakamoto, 1997; Rodriguez Milla et al., 2003). The pathogen-responsive, putative salicylate-glucosyltransferase $U G T 74 F 2$ was co-induced by sulfonylurea herbicides and BXN (Tables 1 and 3). For all other genes combined in this group except for MRP5 and PDR8 (see above), no function or relation to plant stress response had been described so far.

A possible explanation for the correlated induction of effector genes by sulfonylurea and pathogen could be an impact on aromatic amino acid metabolism, which is evoked by the inhibition of the synthesis of branched amino acids by sulfonylurea herbicides. Consequently, plant responses involving compounds derived from aromatic amino acids, such as the reaction to pathogens, might be affected. Sulfonylurea appli- cation could therefore influence the susceptibility of plants towards pathogens and, vice versa, a prevailing infection could alter the sensitivity towards these herbicides.

\section{Independent controls of transcriptional alterations}

In most instances, the expression of GST, CYP, UGT, and $\mathrm{ABC}$ transporter genes previously reported in the literature was in agreement with the array expression analyses (see above; Supplementary Table 2). Discrepancies such as the high expression of MRP5 observed in immature siliques or the lack of SA-induction of GSTF8 in contrast to reported cases could be attributed to different experimental regimes such as the affected organs, age, or timing (Supplementary Table 2).

To further confirm the data obtained with MetArray, the transcript levels of additional genes, which linked the responses to abiotic and biotic stresses, were examined by semi-quantitative RT-PCR. These analyses confirmed the coinduction of CYP71B15, CYP72A8, GSTF2, GSTF6, GSTF7, UGT74F2, and MRP3 by primisulfuron application and Pseudomonas infection (Table 4). In addition, these genes differentiated the reaction to primisulfuron and bromoxynil in agreement with the array analyses; $U G T 74 F 2$ was confirmed to be induced by both herbicides (Tables 1 and 4). However, the quantitative induction values were different for both types of analyses. In most cases, the array induction values were greater than RT-PCR data, which is coherent with the fact that several array induction values were calculated using estimated, low control levels as denominators. Consequently, we never discussed a biological meaning of different induction values.

The probes directed against the highly homologous pairs of phi GSTs, GSTF2/GSTF3 and GSTF6/GSTF7 were likely to cross-react with transcripts from both genes, respectively. Since the array analyses revealed their responsiveness to multiple stimuli, their induction was scrutinized by RT-PCR. The induction of GSTF6, GSTF7 and GSTF2 by PRI, PSavir, SA, MeJA, and ETH was confirmed by RT-PCR (Table 4; Supplementary Table 7). In contrast, GSTF3 was not detected by RT-PCR, although the array induction values were similar due to cross-hybridizing GSTF2 transcripts (Table 4). 


\section{Conclusions}

A. thaliana effector genes involved in consecutive steps of plant secondary metabolism had been chosen for a combined analysis of transcriptional responses to abiotic and biotic stressors. Most of them are encoded by large gene families. In order to distinguish between highly homologous members gene-specific probes derived from 3'-regions were designed. Both the organ-specific expression patterns and the differential stress-responsiveness among members of these gene families emphasize the functional importance of the enormous genetic diversity that has evolved in plants. Although there are highly homologous gene clusters at the sequence level, differential transcriptional regulations along with biochemical data argue against truly redundant functions of members within phylogenetic branches, which had been completely investigated. From an evolutionary point of view Pichersky and Gang (2000) linked the plasticity of plant responses to environmental challenges in particular to the diversification of plant secondary metabolism and the creation of an increasing number of genes with new properties and tasks. As a consequence and manifestation of these diverse functions, the transcriptome of these effector gene families appears to monitor and differentiate plant responses to various environmental cues. This allowed distinguishing three different types of reactions towards the stimuli applied in this study.

Of particular interest was the differentiation of plant responses towards two different exogenous chemicals. This differentiation probably reflects the different modes of action and potential side effects of these compounds. Thus, it highlights the potential of transcriptome analysis based on a focused collection of effector genes for a fast and straightforward analysis of new active compounds. Furthermore, an important overlap between abiotic and biotic stress responses was indicated by the correlation of Arabidopsis transcriptional reaction towards sulfonylurea herbicides and a bacterial pathogen. Such a crosstalk points to potential mutual interactions of pathogen defense and response to (herbicidal) chemicals. The MetArray is a tool to detect such interactions.

Besides these functional relationships and differentiation of stress responses, this study provides initial information on the function of individual genes related to secondary metabolism by pin- pointing individual members to specific or multiple plant stress responses.

\section{Materials and methods}

\section{Plant growth conditions and treatments}

Arabidopsis thaliana Col-0 were raised on soil with about 10 plants per $5 \times 5 \mathrm{~cm}^{2}$ pot using $16 \mathrm{~h}$ light periods $\left(150-200 \mu \mathrm{mol} \mathrm{m} \mathrm{m}^{-2} \mathrm{~s}^{-1}\right)$ at $23 \pm 2{ }^{\circ} \mathrm{C}$. For pathogen infections plants were grown under $12 \mathrm{~h}$ light periods to obtain larger leaves. Leaves (rosette stage before bolting) of control experiments and treatments were harvested in parallel to exclude any diurnal effects. All treatments were done at the rosette stage 2$3 \mathrm{~h}$ after the onset of the light-period and lasted $24 \mathrm{~h}$ except the UV-B irradiation experiment. Biologically independent experiments were repeated three times or four times in two separate settings (UV-B) (Supplementary Tables 5 and 6). The UV-B experiment was conducted as a long term exposure in a sun simulator. After a precultivation period of 5 days, plants were exposed 19 days using a $14 \mathrm{~h}$ light period (PAR $1030 \mu \mathrm{mol} \mathrm{m} \mathrm{m}^{-2} \mathrm{~s}^{-1}$ ) supplemented with $10 \mathrm{~h} \mathrm{UV-}$ $B$ irradiation at $120 \mathrm{~mW} \mathrm{~m}^{-2}$ (biologically effective weighting the spectrum according to Caldwell (1971) and normalization at $300 \mathrm{~nm}$ ). Control plants were grown under glass filters, which cut off UV-B radiation (Ibdah et al., 2002). For herbicide treatments three-week-old Arabidopsis plants were sprayed with $750 \mu \mathrm{g} \mathrm{m}^{-2}$ primisulfuron-methyl, $1.5 \mathrm{mg} \mathrm{m}^{-2}$ prosulfuron, and $1.5 \mathrm{mg} \mathrm{m}^{-2}$ bromoxynil octanoate. The herbicide stock solutions had been diluted 1:1000 with $0.05 \%$ (w/v) Silwet L-77 (Lehle Seeds, TX, USA) and sonified to get an even aqueous suspension. Control plants were treated in the same way with $0.05 \%$ Silwet. There were no visible damages at the harvest. For bacterial infections half the surface of five leaves from five week old Arabidopsis plants were syringe-infiltrated with $P$. syringae pv. tomato DC3000 (avrRpt2) at a titre of $5.5 \times 10^{5}$ colony forming units $\mathrm{ml}^{-1}$ in water. Whole leaves of inoculated and water inoculated control plants were harvested after $24 \mathrm{~h}$. The induction of the molecular markers PR-1 and PDF1.2 was monitored to independently prove the success of pathogen infections (Supplementary Figure 2). 
Treatments with SA, MeJA, and ETH were done as described in Wagner et al. (2002).

For analysis of organ-specific expression patterns plants were grown hydroponically (Gibeaut et al., 1997) with the addition of $0.5 \mathrm{~g} \mathrm{l}^{-1}$ 2-[N-morpholino]ethanesulfonic acid, $\mathrm{pH}$ adjusted to 5.4 with phosphoric acid. Leaves and roots were harvested after 3 weeks, flowers and stems after 5 weeks, immature siliques after 6 weeks.

\section{Nucleic acids}

Total RNA was isolated according to the method described by Chang et al. (1993; PRI, BXN, UVB, organ expression), by Zimmerli et al. (2000; PSavir/ signal molecules), or by Reymond et al. (2000; PRO). All procedures included a $\mathrm{LiCl}$ precipitation as a major and common purification step. After spectrophotometric analyses the amounts of RNA were equalized according to the ethidium bromide fluorescence encompassing the region of $25 \mathrm{~S}$ to $18 \mathrm{~S}$ rRNA bands after gel electrophoresis. Different RNA isolation protocols did not impose a major impact on the expression data; e.g. PRI and PRO data were correlated, although two protocols had been used in different laboratories. See also below (Statistical analysis) for processing of data.

Gene-specific probes were designed and analyzed using ProbeDesign algorithm (see above; Supplementary Table 1; mips.gsf.de/proj/thal/primerDesign/index.html). Probes were PCR-amplified from genomic DNA and cloned into pGEM-Teasy vector (Promega, Madison, WI).

\section{Array production, hybridization and data acquisition}

Specific DNA probes were amplified using flanking vector DNA sequences (Supplementary Table 8). PCR products were concentrated using Multiscreen plates (Millipore, Bedford, MA, USA), resuspended in water, and spotted in duplicate onto Hybond- ${ }^{+}$nylon membranes (Amersham, Freiburg, Germany) using the MicroGrid robot (400 $\mu \mathrm{m}$ pins; BioRobotics, Cambridge, UK). After spotting the filters were crosslinked (UV-Stratalinker 240, Stratagene, La Jolla, USA), denaturated and reference hybridized with $5^{\prime}-\left[{ }^{33} \mathrm{P}\right]$-labeled $\mathrm{T} 7$ oligonucleotide as described by Hauser et al. (1998).
For complex hybridizations total RNA was labeled by oligo-dT-primed cDNA synthesis incorporating $\left[\alpha-{ }^{33} \mathrm{P}\right] \mathrm{dAMP}$ by an MMLV reverse transcriptase according to Hauser et al. (1998) using $30 \mu \mathrm{g}$ RNA and $2.6 \mathrm{MBq}$ of $\left[\alpha{ }^{33} \mathrm{P}\right] \mathrm{dATP}$ $\left(42.9 \mathrm{kBq} \mathrm{pmol}{ }^{-1}\right)$ or according to Ambion StripEZ kit (Ambion, Huntingdon, UK) using $10 \mu \mathrm{g}$ RNA for the UV experiment. Both labeling techniques provided correlated expression data if a single RNA preparation was used (Supplementary Figure 4). DNA arrays were hybridized at $68^{\circ} \mathrm{C}$ in $5 \times \mathrm{SSC}(750 \mathrm{mM} \mathrm{NaCl}, 75 \mathrm{mM}$ trisodium citrate, $\mathrm{pH}$ 7), 5× Denhardt's solution, $0.5 \%$ SDS, $100 \mu \mathrm{g} \mathrm{ml}^{-1}$ denaturated salmon sperm DNA. After final washings at $0.2 \times \mathrm{SSC} / 0.1 \% \mathrm{SDS} / 65^{\circ} \mathrm{C}$ primary data were acquired using a FLA-3000 image reader (Fuji, Düsseldorf, Germany) at a resolution of $50 \mu \mathrm{m}$ and ArrayVision software (Imaging Research Inc., Haverhill, UK). To estimate the sensitivity a synthetic mRNA (pAW109; Applied Biosystems, Darmstadt, Germany) was spiked into the hybridization; $5 \times 10^{7}$ copies $/ 30 \mu \mathrm{g}$ total RNA could be detected. About 300 additional probes encompassing other gene-specific probes and EST clones (Supplementary Table 9) were co-hybridized for normalization based on total gene expression in each experiment (see below). All subsequent statistical analyses such as PCA were solely based on the MetArray probe set.

\section{Data evaluation}

Primary data from individual hybridizations were processed and normalized using the algorithm described by Thimm et al. (2001; haruspex.mpimpgolm.mpg.de/gxdb/).

All expression ratios for treatment vs. control experiments were averaged from three biologically independent experiments. In order to allow division indicating a transcriptional ratio individual hybridization signals that were lower than the twofold, local background were replaced by the lowest sample signal measured on that filter (which could possibly be lower than the twofold local background). Thus, any of these values will be an approximation, but rather an underestimation of the induction, since the non-detected reference expression value would be even lower. However, ratios were labeled n.d. (not detectable), if transcripts were not detected in both control and treatment. Any results, which showed inconsistent, 
up- and down-regulated changes in replica experiments, were labeled 'exp' (Supplementary Tables 4-6). If transcription was only detected in one replication, a mean value was calculated using ratio 1.0 (no change) for the not detectable replicas, unless the resulting mean value would indicate a larger than twofold change. In the latter case, values were not taken into consideration and labeled 'o.o.' (only once; Supplementary Tables 4-6). Ratios smaller than 0.5 or larger than 2.0 were considered for specific discussions about transcriptional changes of individual genes (Tables 13). In a few cases, the three replicas indicated a consistent, but highly divergent induction. Consequently, ratio 2.0 was assigned as a minimal induction level to clearly indicate induction without overestimation. Furthermore, several high induction values were based on approximated, low control values as denominators as described above. In order to avoid any biased influence in further multivariate analyses the maximum induction values were generally limited to $16\left(=2^{4}\right)$ by assigning this value to all inductions higher than 16. For statistical analysis, all values were log-transformed to the basis 2 .

For analysis of organ-specific expressions, individual sets of data were normalized as above. The mean values, representing relative gene activities, were calculated from three biologically independent experiments (Figure 1; Supplementary Table 3). If no transcription above the twofold local background was detected in a single experiment, zero (no detectable expression) was used for calculation of the mean value.

\section{Statistical analysis}

The analysis of MetArray expression data was designed to find a partitioning of genes to specific plant reactions and to explore their concomitant participation in groups of transcriptional responses. Principal component analysis (PCA) was used to analyze how microarray data are structured (Holter et al., 2000, Raychauduri et al., 2000; Landgrebe et al., 2002). PCA was applied to the pre-processed data to identify subsets of genes with large variation between transcriptional responses and to extract groups of correlated responses.

Before drawing conclusions about the relative levels of gene expression systematic effects from non-biological sources should be removed. One step of this data preprocessing is concerned with multiple array normalization or normalization between arrays. Thus, signals from different arrays are calibrated to put them on a comparable scale. Centering and/or scaling are suitable normalization methods (Parmigiani et al., 2003; see below). In order to eliminate non-informative genes in this study, those genes were excluded from the analysis that did not show a twofold deviation in expression ratios after any treatment. Any remaining individual data points, which indicated 'n.d.', 'o.o.', or 'exp', were assigned $\log _{2}=0$ (meaning no change) in order to allow further multivariate analysis (Troyanskaya et al., 2001). The resulting $n \times p$ data matrix $(n=135, p=8)$ was preprocessed in order to calibrate different arrays and to focus the analysis on the differential gene expression for gene $g$ $(g=1, \ldots, n)$ and transcriptional response $j(j=1$, $\ldots, p)$. Therefore, data were standardized with respect to columns (response) and mean-centered with respect to rows (genes). This was done iteratively. Then PCA reduces the dimensionality of the multivariate data to represent the objects (genes) in a reduced space and groups of variables correlating with each other can be extracted. Such groups are represented by new variables, which are linear combinations of original variables. If there are non-zero correlations between the original data, PCA allows reducing dimensions while only slightly reducing information: a large proportion of the variance will be explained by a smaller number of new variables. In a two-dimensional reduced space used in this study the variance for each gene between responses is proportional to the distance to the origin of the plot. Since genes with great variances contribute more significantly to the differentiation of transcriptional responses, the angular distance was used to select genes. It was arbitrarily set at 1.6 resulting in a selection of 46 out of 135 genes. For each gene the angular distance from the $x$-axis describes the relation of this gene to both new variables. Therefore, this parameter was used to rearrange and cluster the data. Subsequently, the original ratios were substituted to create color-coded expression-profile tables of this set of most informative genes (Figure 4).

\section{Verification of MetArray results by $R T-P C R$}

Total RNA samples from replica experiments were pooled and equal amounts $(0.5$ or $1 \mu \mathrm{g})$ were re- 
verse transcribed. Subsequent semi-quantitative PCR was performed using a limited number of PCR cycles that was individually checked to remain in the exponential phase of amplification (Weig et al., 1997; Bovet et al., 2003). The gene for ribosomal protein AtS16 was amplified in parallel and used for normalization. Quantifications were based on ethidium bromide fluorescence or $\left[\alpha-{ }^{33} \mathrm{P}\right]$-dAMP incorporation and phosporimaging (Weig et al., 1997; Bovet et al., 2003). Gene-specific primers and numbers of PCR cycles for GSTF2, GSTF3, GSTF6, GSTF7, UGT74F2, $M R P 3$, and AtS16 are accessible as Supplementary Table 8 . The expression of $C Y P 71 B 15$ and $C Y P 72 A 8$ was examined by real-time PCR using GeneAmp 5700 sequence detection system (Applied Biosystems, Courtaboeuf, France) with SYBR Green I (Roche, Mannheim, Germany). Amplification consisted of 40 cycles $\left(95^{\circ} \mathrm{C} / 15 \mathrm{~s}\right.$, $60{ }^{\circ} \mathrm{C} / 60 \mathrm{~s}$ ). The actin2 gene was used as an internal, constitutively expressed standard of each cDNA sample. Primers are listed in Supplementary Table 8. Quantification of gene expression was performed using the cycle threshold method relatively to a calibrator (defined for each target with cDNA dilutions). All analyses were run at least in duplicate. Mean values were calculated for relative expression ratios.

\section{Acknowledgements}

We are indebted to Dr. Sebastian Kloska (MaxPlanck-Institute of Molecular Plant Physiology, Golm, Germany) for access to their array evaluation software Haruspex. We also thank Drs. Dawn Little and Jörg Durner for critical reading. The work was in part supported by Bayerisches Staatsministerium für Wissenschaft, Forschung und Kunst (bayforuv) and the Swiss National Science Foundation (31-45682.95). Support of Aventis Agro to A.H. is gratefully acknowledged.

\section{References}

Bak, S., Tax, F.E., Feldmann, K.A., Galbraith, D.W. and Feyereisen, R. 2001. CYP83B1, a cytochrome P450 at the metabolic branch point in auxin and indole glucosinolate biosynthesis in Arabidopsis. Plant Cell 13: 101-111.

Batard, Y., Schalk, M., Pierrel, M.A., Zimmerlin, A., Durst, F. and Werck-Reichhart, D. 1997. Regulation of the cinnamate 4-hydroxylase (CYP73A1) in Jerusalem artichoke tubers in response to wounding and chemical treatments. Plant Physiol. 113: 951-959.

Bell-Lelong, D.A., Cusumano, J.C., Meyer, K. and Chapple, C. 1997. Cinnamate-4-hydroxylase expression in Arabidopsis. Regulation in response to development and the environment. Plant Physiol. 113: 729-738.

Bovet, L., Eggmann, T., Meylan-Bettex, M., Polier, J., Kammer, P., Marin, E., Feller, U. and Martinoia, E. 2003. Transcript levels of AtMRPs: induction of AtMRP3 after cadmium treatments. Plant Cell Environ. 26: 371-381.

Caldwell, M.M. 1971. Solar ultraviolet radiation and the growth and development of higher plants. In: A.C. Giese (Ed.), Photophysiology, Vol. 6. Academic Press, New York, pp. 131-177.

Chang, S., Puryear, J. and Cairney, J. 1993. A simple and efficient method for isolating RNA from pine trees. Plant Mol. Biol. Rep. 11: 113-116.

Chapple, C. 1998. Molecular genetics analysis of plant cytochrome P450-dependent monooxygenases. Ann. Rev. Plant Physiol. Plant Mol. Biol. 49: 311-343.

Cheong, Y.H., Chang, H.-S., Gupta, R., Wang, X., Zhu, T. and Luan, S. 2002. Transcriptional profiling reveals novel interactions between wounding, pathogen, abiotic stress, and hormonal responses in Arabidopsis. Plant Physiol. 129: 661-677.

Coleman, J.O.D., Blake-Klaff, M.M.A. and Davies, T.G.E. 1997. Detoxification of xenobiotics by plants: chemical modification and vacuolar compartmentation. Trends Plant Sci. 2: 144-151.

Davies, T.G.E. and Coleman, J.O.D. 2000. The Arabidopsis thaliana ATP-binding cassette proteins: an emerging superfamily. Plant Cell Environ. 23: 431-443.

Dixon, D.P., Cole, D.J. and Edwards, R. 2000. Characterisation of a zeta class glutathione transferase from Arabidopsis thaliana with a putative role in tyrosine catabolism. Arch. Biochem. Biophys. 384: 407-412.

Dixon, D.P., Lapthorn, A. and Edwards, R. 2002. Plant glutathione transferases. Genome Biol. 3: 3004.1-3004.10.

Dong, X. 1998. SA, JA, ethylene, and disease resistance in plants. Curr. Opin. Plant Biol. 1: 316-323.

Edwards, R. and Dixon, D.P. 2000. The role of glutathione transferases in herbicide metabolism. In: A.H. Cobb and R.C. Kirkwood (Eds.), Herbicides and their Mechanism of Action. Sheffield Academic Press, Sheffield, pp. 33-71.

Edwards, R., Dixon, D.P. and Walbot, V. 2000. Plant glutathione $S$-transferases: enzymes with multiple functions in sickness and in health. Trends Plant Sci. 5: 193-198.

Gaedeke, N., Klein, M., Kolukisaoglu, Ü., Forestier, C., Müller, A., Ansorge, M., Becker, D., Mamnun, Y., Kuchler, K., Schulz, B., Müller-Röber, B. and Martinoia, E. 2001. The Arabidopsis thaliana ABC transporter AtMRP5 controls root development and stomata movement. EMBO J. 20: 18751887.

Gibeaut, D.M., Hulett, J., Cramer, G.R. and Seemann, J.R. 1997. Maximal biomass of Arabidopsis thaliana using a simple, low-maintenance hydroponic method and favorable environmental conditions. Plant Physiol. 115: 317-319.

Godiard, L., Sauviac, L., Dalbin, N., Liaubet, L., Callard, D., Czernic, P. and Marco, Y. 1998. CYP76C2, an Arabidopsis thaliana cytochrome $\mathrm{P} 450$ gene expressed during hypersensitive and developmental cell death. FEBS Lett. 438: 245-249. 
Gonneau, M., Mornet, R. and Laloue, M. 1998. A Nicotiana plumbaginifolia protein labeled with an azido cytokinin agonist is a glutathione S-transferase. Physiol. Plant 103: 114-124.

Graham, S.E. and Peterson, J.A. 1999. How similar are P450s and what can their differences teach us. Arch. Biochem. Biophys. 369: 24-29.

Hauser, N.C., Vingron, M., Scheideler, M., Krems, B., Hellmuth, K., Entian, K.-D. and Hoheisel, J.D. 1998. Transcriptional profiling on all open reading frames of Saccharomyces cerevisiae. Yeast 14: 1209-1221.

Holter, N.S., Mitra, M., Maritan, A., Cieplak, M., Banavar, J.R. and Fedoroff, N.V. 2000. Fundamental patterns underlying gene expression profiles: simplicity from complexity. Proc. Natl. Acad. Sci. USA 97: 8409-8414.

Ibdah, M., Krins, A., Seidlitz, H.K., Heller, W., Strack, D. and Vogt, T. 2002. Spectral dependence of flavonol and betacyanin accumulation in Mesembryanthemum crystallinum under enhanced ultraviolet radiation. Plant Cell Environ. 25: 11451154.

Jackson, R.G., Kowalczyk, M., Li, Y., Higgins, G., Ross, J., Sandberg, G. and Bowles, D.J. 2002. Over-expression of an Arabidopsis gene encoding a glucosyltransferase of indole-3acetic acid: phenotypic characterisation of transgenic lines. Plant J. 32: 573-583.

Jackson, R.G., Lim, E.-K., Li, Y., Kowalczyk, M., Sandberg, G., Hoggett, J., Ashford, D.A. and Bowles, D.J. 2001. Identification and biochemical characterization of an Arabidopsis indole-3-acetic acid glucosyltransferase. J. Biol. Chem. 276: 4350-4356.

Jasinski, M., Stukkens, Y., Degand, H., Purnelle, B., Marchand-Brynaert, J. and Boutry, M. 2001. A plant plasma membrane ATP binding cassette-type transporter is involved in antifungal terpenoid secretion. Plant Cell 13: 10951107.

Jin, H., Cominelli, E., Bailey, P., Parr, A., Mehrtens, F., Jones, J., Tonelli, C., Weisshaar, B. and Martin, C. 2000. Transcriptional repression by AtMYB4 controls production of UV-protecting sunscreens in Arabidopsis. EMBO J. 19: 61506161.

Jones, P. and Vogt, T. 2001. Glycosyltransferases in secondary plant metabolism: tranquilizers and stimulant controllers. Planta 213: 164-174.

Jones, P.R., Messner, B., Nakajima, J.-J., Schäffner, A.R. and Saito, K. 2003. UGT73C6 and UGT78D1-glycosyltransferases involved in flavonol glycoside biosynthesis in Arabidopsis thaliana. J. Biol. Chem. 278: 43910-43918.

Kahn, R. and Durst, F. 2000. Function and evolution of plant cytochrome P450. Recent Adv. Phytochem. 34: 151189.

Kampranis, S.C., Damianova, R., Atallah, M., Toby, G., Kondi, G., Tsichlis, P.N. and Makris, A.M. 2000. A novel plant glutathione $S$-transferase/peroxidase suppresses Bax lethality in yeast. J. Biol. Chem. 275: 29207-29216.

Kolukisaoglu, Ü., Bovet, L., Klein, M., Eggmann, T., Geisler, M., Wanke, D., Martinoia, E. and Schulz, B. 2002. Family business: The multidrug-resistance related protein (MRP) ABC transporter genes in Arabidopsis thaliana. Planta 216: $107-119$.

Kreuz, K. and Martinoia, E. 1999. Herbicide metabolism in plants: Integrated pathways of detoxification. In: G.T.
Brooks and T.R. Roberts (Eds.), The Proceedings of the 9th International Congress on Pesticide Chemistry: The Food-Environment Challenge. The Royal Society of Chemistry, London, pp. 279-287.

Kunkel, B.N. and Brooks, D.M. 2002. Cross talk between signalling pathways in pathogen defense. Curr. Opin. Plant Biol. 5: 325-331.

Landgrebe, J., Wurst, W. and Welzl, G. 2002. Permutationvalidated principal component analysis of microarray data. Genome Biol. 3: 0019.1-0019.11.

Li, Y., Baldauf, S., Lim, E.-K. and Bowles, D.J. 2001. Phylogenetic analysis of the UDP-glycosyltransferase multigene family of Arabidopsis thaliana. J. Biol. Chem. 276, 43384343.

Lim, E., Doucet, C.J., Li, Y., Elias, L., Worrall, D., Spencer, S.P., Ross, J. and Bowles, D.J. 2002. The activity of Arabidopsis glycosyltransferases toward salicylic acid, 4hydroxybenzoic acid, and other benzoates. J. Biol. Chem. 277: 586-592.

Lim, E.-K., Li, Y., Parr, A., Jackson, R., Ashford, D.A. and Bowles, D.J. 2001. Identification of glucosyltransferase genes involved in sinapate metabolism and lignin synthesis in Arabidopsis. J. Biol. Chem. 276: 4344-4349.

Loutre, C., Dixon, D.P., Brazier, M., Slater, M., Cole, D.J. and Edwards, R. 2003. Isolation of a glucosyltransferase from Arabidopsis thaliana active in the metabolism of the persistent pollutant 3,4-dichloroaniline. Plant J. 34: 485-493.

Loyall, L., Uchida, K., Braun, S., Furuya, M. and Frohnmeyer, H. 2000. Glutathione and a UV light-induced glutathione $S$ transferase are involved in signaling to chalcone synthase in cell cultures. Plant Cell 12: 1939-1950.

Maleck, K., Levine, A., Eulgem, T., Morgan, A., Schmid, J., Lawton, K.A., Dangl, J.L. and Dietrich, R.A. 2000. The transcriptome of Arabidopsis thaliana during systemic acquired resistance. Nature Genet. 26: 403-410.

Mansuy, D. 1998. The great diversity of reactions catalyzed by cytochrome P450. Comp. Biochem. Physiol. Part. C. 121: 514.

Marrs, K.A. 1996. The functions and regulation of glutathione $S$-transferases in plants. Ann. Rev. Plant Physiol. Plant Mol. Biol. 47: 127-158.

Martinoia, E., Klein, M., Geisler, M., Bovet, L., Forestier, C., Kolukisaoglu, Ü., Müller-Röber, B. and Schulz, B. 2002. Multifunctionality of plant $\mathrm{ABC}$ transporters - more than just detoxifiers. Planta 214: 345-355.

Mazel, A. and Levine, A. 2002. Induction of glucosyltransferase transcription and activity during superoxide-dependent cell death in Arabidopsis plants. Plant Physiol. Biochem. 40: 133140

Messner, B., Thulke, O. and Schäffner, A.R. 2003. Arabidopsis glucosyltransferases with activities toward both endogenous and xenobiotic substrates. Planta 217: 138-146.

Mikkelsen, M.D., Petersen, B.L., Glawischnig, E., Jensen, A.B., Andreasson, E. and Halkier, B.A. 2003. Modulation of CYP79 genes and glucosinolate profiles in Arabidopsis by defense signaling pathways. Plant Physiol. 131: 298-308.

Milkowski, C., Baumert, A. and Strack, D. 2000. Identification of four Arabidopsis genes encoding hydroxycinnamate glucosyltransferases. FEBS Lett. 486: 183-184.

Mizutani, M., Ohta, D. and Sato, R. 1997. Isolation of a cDNA and a genomic clone encoding cinnamate 4-hydroxylase from 
Arabidopsis and its expression manner in planta. Plant Physiol. 113: 755-763.

Mizutani, M., Ward, E. and Ohta, D. 1998. Cytochrome P450 superfamily in Arabidopsis thaliana: Isolation of cDNAs, differential expression, and RFLP mapping of multiple cytochromes P450. Plant Mol. Biol. 37: 39-52.

Mullineaux, P.M., Karpinski, S., Jimenez, A., Cleary, S.P., Robinson, C. and Creissen, G.P. 1998. Identification of cDNAS encoding plastid-targeted glutathione peroxidase. Plant J. 13: 375-379.

Noctor, G., Gomez, L., Vanacker, H. and Foyer, C.H. 2002. Interactions between biosynthesis, compartmentation and transport in the control of glutathione homeostasis and signalling. J. Exp. Bot. 53: 1283-1304.

Page, R.D.M. 1996. TREEVIEW: an application to display phylogenetic trees on personal computers. Comput. Appl. Biosci. 12: 357-358.

Paquette, S. M., Møller, B.L. and Bak, S. 2003. On the origin of family 1 plant glycosyltransferases. Phytochemistry 62: 399413.

Parmigiani, G., Garrett, E.S., Irizarry, R.A. and Zeger, S.L. 2003. The Analysis of Gene Expression Data: Methods and Software. Springer, New York.

Penninckx, I.A.M.A., Thomma, B.P.H.J., Buchala, A., Métraux, J.-P. and Broekaert, W.F. 1998. Concomitant activation of jasmonate and ethylene response pathways is required for induction of a plant defensin gene in Arabidopsis. Plant Cell 10: 2103-2113.

Pichersky, E. and Gang, D.R. 2000. Genetics and biochemistry of secondary metabolites in plants: An evolutionary perspective. Trends Plant Sci. 5: 439-445.

Raychaudhuri, S., Stuart, J. and Altman, R. 2000. Principal component analysis to summarize microarray experiments: application to sporulation time series. In: Pacific Symposium on Biocomputing, Vol. 5, pp. 455-466.

Reymond, P., Weber, H., Damond, M. and Farmer, E. 2000. Differential gene expression in response to mechanical wounding and insect feeding in Arabidopsis. Plant Cell 12: 707-720.

Rodriguez Milla, M.A., Maurer, A., Rodriguez Huete, A. and Gustafson, J.P. 2003. Glutathione peroxidase genes in Arabidopsis are ubiquitous and regulated by abiotic stresses through diverse signaling pathways. Plant J. 36: 602-615.

Ross, J., Li, Y., Lim, E. and Bowles, D.J. 2001. Protein family review. Higher plant glycosyltransferases. Genome Biol. 2: 3004.1-3004.6.

Sánchez-Fernández, R., Davies, T.G.E., Coleman, J.O.D. and Rea, P.A. 2001. The Arabidopsis thaliana ABC protein superfamily, a complete inventory. J. Biol. Chem. 276: 30231-30244.

Sandermann, H.Jr. 1994. Higher plant metabolism of xenobiotics: the 'green liver' concept. Pharmacogenetics 4: 225-241.

Sasabe, M., Toyoda, K., Shiraishi, T., Inagaki, Y., Ichinose, Y. 2002. cDNA cloning and characterization of tobacco ABC transporter: NtPDR1 is a novel elicitor-responsive gene. FEBS Lett. 518: 164-168.

Schalk, M., Pierrel, M.A., Zimmerlin, A., Batard, Y., Durst, F. and Werck-Reichhart, D. 1997. Xenobiotics: substrates and inhibitors of the plant P450s. Environ. Sci. Pol. Res. 4: 229-234.
Schaller, B., Schneider, B. and Schütte, R.H. 1992. Metabolism of the herbicide bromoxynil in Hordeum vulgare and Stellaria media. Z. Naturforsch. 47c: 126-131.

Schenk, P.M., Kazan, K., Wilson, I., Anderson, J.P., Richmond, T., Somerville, S.C. and Manners, J.M. 2000. Coordinated plant defense responses in Arabidopsis revealed by microarray analysis. Proc. Natl. Acad. Sci. USA 97: 11655-11660.

Schoch, G.A., Nikov, G.N., Alworth, W.L. and WerckReichhart, D. 2002. Chemical inactivation of the cinnamate 4-hydroxylase allows for the accumulation of salicylic acid in elicited cells. Plant Physiol. 130: 1022-1031.

Schuler, M.A. and Werck-Reichhart, D. 2003. Functional genomics of P450s. Ann. Rev. Plant Phys. Plant Mol. Biol. 54: 629-667.

Smart, C.C. and Fleming, A.J. 1996. Hormonal and environmental regulation of a plant PDR5-like $\mathrm{ABC}$ transporter. J. Biol. Chem. 271: 19351-19357.

Smith, A.P., Nourizadeh, S.D., Peer, W.A., Xu, J., Bandyopadhyay, A., Murphy, A.S. and Goldsbrough, P.B. 2003. Arabidopsis AtGSTF2 is regulated by ethylene and auxin, and encodes a glutathione S-transferase that interacts with flavonoids. Plant J. 36: 433-442.

Sugimoto, M. and Sakamoto, W. 1997. Putative phospholipid hydroperoxide glutathione peroxidase gene from Arabidopsis thaliana induced by oxidative stress. Genes Genet. Syst. 72: 311-316.

Surplus, S.L., Jordan, B.R., Murphy, A.M., Carr, J.P., Thomas, B. and A.-H.-Mackerness, S. 1998. Ultraviolet-Binduced responses in Arabidopsis thaliana: Role of salicylic acid and reactive oxygen species in the regulation of transcripts encoding photosynthetic and acidic pathogenesis-related proteins. Plant Cell Environ. 21: 685-694.

Thara, V.K., Tang, X., Gu, Y.Q., Martin, G.B. and Zhou, J.M. 1999. Pseudomonas syringae pv tomato induces the expression of tomato EREBP-like genes Pti4 and Pti5 independent of ethylene, salicylate and jasmonate. Plant J. 20: 475-483.

Thimm, O., Essigmann, B., Kloska, S., Altmann, T. and Buckhout, T.J. 2001. Response of Arabidopsis to iron deficiency stress as revealed by microarray analysis. Plant Physiol. 127: 1030-1043.

Thompson, J.D., Higgins, D.G. and Gibson, T.J. 1994. CLUSTAL W: improving the sensitivity of progressive multiple sequence alignment through sequence weighting, position-specific gap penalties and weight matrix choice. Nucleic Acids Res. 22: 4673-4680.

Thornalley, P.J. 1990. The glyoxalase system: New developments towards functional characterization of a metabolic pathway fundamental to biological life. Biochem J. 269: 1-11.

Tommasini, R., Vogt, E., Schmid, J., Fromentau, M., Amrhein, N. and Martinoia, E. 1997. Differential expression of genes coding for $\mathrm{ABC}$ transporters after treatment of Arabidopsis thaliana with xenobiotics. FEBS Lett. 411: 206-210.

Troyanskaya, O., Cantor, M., Sherlock, G., Brown, P., Hastie, T., Tibshirani, R., Botstein, D. and Altman, R.B. 2001. Missing value estimation methods for DNA microarrays. Bioinformatics 17: 520-525.

van den Brûle, S. and Smart, C.C. 2002. The plant PDR family of ABC transporters. Planta 216: 95-106.

van den Brûle, S., Müller, A., Fleming, A.J. and Smart, C.C. 2002. The ABC transporter SpTUR2 confers resistance to the antifungal diterpene sclareol. Plant J. 30: 649-662. 
Wagner, U., Edwards, R., Dixon, D.P. and Mauch, F. 2002 Probing the diversity of the Arabidopsis glutathione S-transferase gene family. Plant Mol. Biol. 49: 515-532.

Warnecke, D.C., Baltrusch, M., Buck, F., Wolter, F.P. and Heinz, E. 1997. UDP-glucose:sterol glucosyltransferase: cloning and functional expression in Escherichia coli. Plant Mol. Biol. 35: 597-603.

Weig, A., Deswarte, C. and Chrispeels, M.J. 1997. The major intrinsic protein family of Arabidopsis has 23 members that form three distinct groups with functional aquaporins in each group. Plant Physiol. 114: 1347-1357.

Werck-Reichhart, D., Bak, S. and Paquette, S. 2002. Cytochromes P450. In: C.R. Somerville and E.M. Meyerowitz (Eds.), The Arabidopsis Book, American Society of Plant Biologists, Rockville, MD, http://www.aspb.org/publications/arabidopsis/.
Xu, W., Bak, S., Decker, A., Paquette, S.M., Feyereisen, R. and Galbraith, D.W. 2001. Microarray-based analysis of gene expression in very large gene families: the cytochrome $\mathrm{P} 450$ gene superfamily of Arabidopsis thaliana. Gene 272: 61-74.

Xu, Y., Chang, P.F.L., Liu, D., Narasimhan, M. L., Raghothama, K. G., Hasegawa, P.M. and Bressan, R.A. 1994. Plant defense genes are synergistically induced by ethylene and methyl jasmonate. Plant Cell 6: 1077-1085.

Zhou, N., Tootle, T.L. and Glazebrook, J. 1999. Arabidopsis $P A D 3$, a gene required for camalexin biosynthesis encodes a putative cytochrome P450 monooxygenase. Plant Cell 11: 2419-2428.

Zimmerli, L., Jakab, G., Metraux, J.-P. and Mauch-Mani, B. 2000. Potentiation of pathogen-specific defense mechanisms in Arabidopsis by $\beta$-aminobutyric acid. Proc. Natl. Acad. Sci. USA 97: $12920-12925$. 